\title{
El pasado reciente de Argentina en el cruce de temporalidades múltiples. Una reflexión situada en dos experiencias de investigación microsociales
}

Andrea Belén Rodríguez* Ana Inés Seitr.*

\section{Resumen}

El trabajo analiza las potencialidades que emergen del abordaje del estudio de ciertos acontecimientos y procesos del pasado reciente de Argentina desde escalas temporales múltiples. El punto de partida de esta reflexión lo constituyen nuestras investigaciones que se centran en el estudio de las subjetividades, vivencias y representaciones de diversos actores sociales en la última dictadura militar argentina (1976-1983) y en el marco del Conflicto del Atlántico Sur (1982) desde una perspectiva microanalítica. En el artículo, pues, exploramos distintas formas en que el cruce entre diversas temporalidades es fundamental para enriquecer la comprensión situada e histórica de las experiencias y percepciones de los sujetos estudiados.

El trabajo está organizado en torno a tres momentos. En el primero, realizamos un recorrido sobre el uso de distintas escalas temporales en la historiografía de las actitudes sociales en la última dictadura militar y en la guerra de Malvinas. A partir de este examen, abordamos las potencialidades del cruce de distintas duraciones para comprender las experiencias, prácticas y representaciones de los actores. Finalmente, reflexionamos sobre la necesidad que tienen en común nuestras investigaciones de considerar determinadas variables y contextos que se insertan en temporalidades múltiples, así como los efectos de este análisis en la comprensión histórica de ambos objetos de indagación.

* IPEHCS (CONICET-Universidad Nacional del Comahue)-Universidad Nacional del Sur. E mail: andrea_belen_rodriguez@yahoo.com

** Universidad Nacional del Sur. Universidad Nacional de La Plata. E mail: anaiseitz@gmail.com 
Palabras clave: pasado reciente - Argentina - escalas temporales

\section{Summary}

The work analyzes the potentialities that emerge from the approach to the study of certain phenomena, processes and/or dimensions of the recent past of Argentina from multiple temporal scales. The starting point of this reflection is our research that focuses on the study of the subjectivities, experiences and representations of various social actors in the last Argentine military dictatorship (1976-1983) and in the framework of the South Atlantic conflict (1982) from a microanalytical perspective. In the paper, therefore, we explore the different ways in which the intersection between different temporalities are fundamental to enrich the situated and historical understanding of the experiences and perceptions of the social actors studied.

The work is organized around three moments. In the first, we make a balance of the use of different temporal scales in the historiography of social attitudes in the last military dictatorship and in the Malvinas war. From this examination, we approach the potentialities of crossing different durations to understand the experiences, practices and representations of the actors. Finally, we reflect on the need that our research has in common to consider certain variables and contexts that are inserted in multiple temporalities, as well as the effects of this analysis on the historical understanding of both objects of inquiry.

Keywords: recent past- Argentine- temporal scales

\section{Introducción}

El objetivo de este trabajo es analizar las potencialidades que emergen del abordaje del estudio de ciertos fenómenos, procesos y/o dimensiones del pasado reciente de Argentina desde escalas temporales múltiples. Nos proponemos, concretamente, valorar los efectos en la interpretación histórica del recurso a un análisis del pasado que integra temporalidades diversas.

El punto de partida de esta reflexión lo constituyen nuestras pesquisas sobre distintas dimensiones vinculadas a las relaciones entre la sociedad y el régimen militar en la última dictadura argentina (1976-1983), desde una perspectiva microanalítica centrada en el estudio de subjetividades, vivencias y representaciones. Tanto la investigación de Ana Inés Seitz sobre las actitudes y comportamientos sociopolíticos de la gente corriente ${ }^{1}$

1 La categoría de gente corriente es objeto de un extenso debate sobre su contenido y alcance, que hemos abordado brevemente en Seitz, 2015. Coincidimos, en gran medida, con la definición que da Daniel Lvovich: "personas con o sin militancia política, no pertenecientes a la dirección de organizaciones politicas o sociales", Lvovich, 2013: 123. Asimismo, es relevante considerar los modos en que Andrew Stuart Bergerson conceptualiza el concepto de corriente, entendiendo de esta manera, desde la perspectiva de los actores, a quienes se autodefinen y se piensan a sí mismos y a sus acciones al margen de la "Historia escrita en 
en el autodenominado "Proceso de Reorganización Nacional", como la de Andrea Belén Rodríguez sobre las experiencias de los no combatientes en la guerra de Malvinas, ${ }^{2}$ abordan distintos modos de construir sentido por parte de actores sociales contemporáneos a los acontecimientos desde un enfoque historiográfico sociocultural. En el texto nos proponemos, pues, explorar distintas formas en que la articulación de temporalidades diversas es fundamental para enriquecer la comprensión situada e histórica de las experiencias y significados/lecturas de los actores estudiados.

El trabajo se ancla en la concepción de que la realidad social pasada está constituida por cambios y permanencias, asociados a ritmos y velocidades diferentes en las transformaciones sociales y que encierran una complejidad de procesos que simultáneamente interactúan, se modifican, se aceleran o permanecen. El análisis historiográfico implica, pues, partir de una compresión del tiempo -entendido en su dimensión de categoría de la ciencia histórica- que engloba duraciones cualitativamente diferentes en la búsqueda de comprensiones complejas de los fenómenos pasados, de sus tramas sociales y de la heterogeneidad de contextos que los componen.

En tanto nos proponemos sopesar algunas formas en que una indagación fundada en diferentes escalas temporales permite construir explicaciones más ricas sobre experiencias sociales que forman parte del pasado reciente ${ }^{3}-$ o pasado presente -, es necesario hacer algunas referencias generales sobre las características de este tiempo histórico y social. Siguiendo a Julio Aróstegui, si bien al presente se lo suele acotar a lo instantáneo y lo fugaz, la noción del ahora, de la ruptura, "comporta igualmente la connotación de la duración, del siempre, de la permanencia". Es nodal tener en cuenta esa

grande", circunscribiendo así sus responsabilidades en ella. Se trata de personas que, como señala el autor, viven en un "autoengaño de inocencia”, Bergerson, 2004: 6 (la traducción es nuestra). En este artículo se utilizarán como sinónimos las nociones de gente corriente, gente común, ciudadanos comunes y ciudadanos de a pie.

2 Ana Inés Seitz estudia las relaciones entre la sociedad y el régimen militar durante la última dictadura en Argentina (1976-1983). Concretamente, se centra en el examen de las actitudes sociopolíticas de la gente corriente en Bahía Blanca en dicho período. Por su parte, Andrea Belén Rodríguez investiga las formas en que la sociedad neuquina vivió la guerra de Malvinas, haciendo foco en los diversos comportamientos e interpretaciones del conflicto de los distintos actores sociales que permanecieron en el continente.

3 Coincidimos con Franco \& Levin cuando caracterizan al pasado reciente de la siguiente forma: "se trata de un pasado abierto, de algún modo inconcluso, cuyos efectos en los procesos individuales y colectivos se extienden hacia nosotros y se nos vuelven presentes", Franco \& Levin, 2007: 31. 
"convergencia de temporalidades" en el presente - esa dialéctica "intrincada pero discernible" entre el instante y la duración - para aprehenderlo en toda su complejidad. ${ }^{4}$ Incluso para abordar aquellos acontecimientos límites, medulares, que implicaron rupturas excepcionales y traumáticas en el siglo XX, como la última dictadura militar y la guerra de Malvinas para la historia argentina, el cruce de esas distintas temporalidades se revela como fundamental. Como plantea lúcidamente Enzo Traverso, aun hechos de tal densidad y "singularidad histórica" como el Holocausto y el nazismo, tienen una "bistoria que no puede ser comprendida si nos limitamos exclusivamente a las fronteras geográficas de Alemania y, desde el punto de vista temporal, al siglo XX; su estudio requiere adoptar una perspectiva diacrónica y comparada a la vez"; requiere, en fin, "considerar simultáneamente la irreductible singularidad del acontecimiento y su inscripción en los "tiempos largos" de la historia". 5

Como es evidente, proponemos un abordaje que, en términos generales, toma como punto de referencia la teoría braudeliana de las tres temporalidades para el abordaje de un proceso histórico-social (la corta, mediana y larga duración, o, en otras palabras, acontecimiento, coyuntura y estructura), aunque sin otorgarle prioridad a ninguna de ellas (a diferencia de Fernand Braudel que veía en la estructura la clave de la explicación histórica). ${ }^{6} \mathrm{Y}$ ello porque consideramos, por un lado, que un examen centrado en el corto plazo en que se sitúan las experiencias de los actores, en los sentidos otorgados a lo vivido en su propia coyuntura, permite complejizar periodizaciones e interpretaciones tradicionales del campo historiográfico sobre el periodo. Pero, por otro lado, sostenemos que situar determinados acontecimientos, procesos y dimensiones del pasado reciente argentino en una temporalidad de alcance mayor hace posible comprender la especificidad de los mismos, su singularidad, así como los rasgos compartidos con otros previos y las tendencias de largo y medio plazo y, también, superar las perspectivas y lecturas de los protagonistas.

El artículo está organizado en torno a tres momentos. En un comienzo, realizamos un recorrido sobre el uso de distintas escalas temporales en la historiografía de las dimensiones sociales de la última dictadura militar y de la guerra de Malvinas, específicamente en los estudios de las actitudes sociopolíticas de la gente corriente hacia

4 Aróstegui, 2004: 91.

5 Traverso, 2003: 12-13.

6 Aguirre Rojas, 1999. 
el régimen y de las experiencias bélicas de quienes permanecieron en el continente. A partir de este examen, abordamos las potencialidades del cruce de distintas temporalidades para comprender las experiencias, prácticas y representaciones de los actores a partir de dos maneras de entender la integración de duraciones diversas. En primer lugar, como una opción teórico metodológica elegida por las investigadoras, y, en segundo lugar, como un camino al que nos "invitan" nuestros propios objetos de estudio, como dimensión propia de estos, en tanto los sujetos investigados producen prácticas y sentidos que inscriben sus trayectorias en las articulaciones de distintas escalas temporales, las cuales incluso ellos mismos explicitan en sus testimonios. Finalmente, reflexionamos sobre la necesidad que tienen en común nuestras pesquisas de considerar determinadas variables y contextos que se insertan en temporalidades múltiples - tanto de larga como de mediana y corta duración - así como los efectos de este análisis en la comprensión histórica de ambos objetos de indagación.

\section{La historiografía de las actitudes sociales en dictadura: entre la excepcionalidad y la normalidad, la continuidad y la ruptura}

Como indicamos, la apuesta por una perspectiva historiográfica que priorice el diálogo entre escalas temporales múltiples no es para nada novedosa: la propuesta braudeliana de las tres temporalidades se remonta a la segunda generación de Annales (1956-1968). ${ }^{7}$ Sin embargo, creemos que es nodal retomar este planteo teórico sobre el tiempo histórico para reflexionar sobre los modos de abordaje del pasado reciente argentino, ya que en ocasiones la historiografía sobre el período ha tendido a primar las interpretaciones basadas en una de las duraciones en forma excluyente, desconociendo o dejando en un segundo plano las otras, lo que ha empobrecido su comprensión.

En el caso del campo de estudios sobre las actitudes y comportamientos sociopolíticos de la gente corriente durante la última dictadura militar argentina, este es aún incipiente y las investigaciones son escasas. ${ }^{8}$ Entre ellas, predominan las indagaciones que

7 Aguirre Rojas, 1999: 101.

8 Para un balance crítico de dicha historiografía, ver Lvovich, 2018. 
privilegian una perspectiva de corto plazo. En algunos de estos trabajos se procura enmarcar los objetos de estudio en una temporalidad más amplia, recuperando de manera general algunas tendencias de más larga duración que se inician en distintos contextos históricos (entre los que prevalecen el primer gobierno peronista o las nuevas condiciones que en distintas dimensiones instauró la autodenominada "Revolución Libertadora" en 1955). Sin embargo, en estos casos la indagación empírica se centra en el período que abre el golpe de Estado de 1976 o, también, en el que inicia la presidencia de Héctor Cámpora en 1973, extendiéndose, en general, hasta 1983.

Una perspectiva de análisis centrada en la corta duración puede generar algunos efectos problemáticos en la interpretación. Entre estos, el excesivo énfasis en la excepcionalidad del acontecimiento o proceso estudiado se evidencia, concretamente, en el concepto de "dictadura cívico-militar", cuyo uso se ha extendido en los últimos años en el espacio público, pero también en cierta medida en el ámbito académico. Esta noción remarca el consenso, el apoyo activo e incluso la colaboración que el régimen encontró en la sociedad, en particular, en diversos sectores de poder como los empresariales, judiciales, políticos y eclesiásticos. Entre algunas de las dificultades que tiene este concepto para dar cuenta del período 1976-1983, ${ }^{9}$ en este trabajo nos interesa revisar aquellas ligadas a las diversas duraciones. En este sentido, una perspectiva temporal más amplia, al inscribir al autodenominado "Proceso de Reorganización Nacional" en el largo plazo, hace posible revisar este supuesto rasgo distintivo de la última dictadura al permitirnos reconocer que el consentimiento, la adhesión activa e incluso la participación de parte de distintos sectores de la sociedad civil se dio también en los otros regímenes militares instaurados en el país desde mediados del siglo pasado. Tal como señala Marina Franco, "en cualquiera de las formas que dan cuenta de la presencia de lo civil, ninguna dictadura argentina de la segunda parte del siglo XX fue otra cosa que civily militar a la vez". por lo que "cuando nos referimos a la última con ese calificativo [dictadura cívico-militar] me parece que no estamos diciendo nada que logre clarificar la especificidad de ese régimen". ${ }^{10}$

$9 \mathrm{Al}$ respecto, ver Franco, 2014, Montero, 2016.

10 Franco, 2014: 87. 
Por otra parte, las interpretaciones de las actitudes sociopolíticas de la gente corriente que recurren a perspectivas de más larga duración, procurando identificar tendencias y continuidades que se extienden durante décadas, también pueden adolecer de límites. Estos se hacen evidentes en un trabajo como el de Sebastián Carassai, ${ }^{11}$ en el que procura construir una interpretación de largo plazo sobre las actitudes de la clase media frente a la violencia en Argentina en los setenta. El autor señala que dichos sectores sociales habrían sostenido un antiperonismo prácticamente inalterado desde 1945 hasta el presente y que este constituye la variable explicativa de sus comportamientos, representaciones y valoraciones durante la década señalada. De esta manera, obvia la historización de este posicionamiento a lo largo de los sucesivos contextos históricos que considera, al no analizar las transformaciones a lo largo del tiempo en estas ideas, sus ajustes y sus matices. En primer lugar, como más evidentes, los efectos que genera el recambio generacional. ${ }^{12}$

En cuanto a la guerra de Malvinas, la historiografía del conflicto también ha estado marcada por esas mismas limitaciones. Desde la inmediata posguerra diversos actores colectivos construyeron dos formas mutuamente excluyentes de comprender el conflicto, que además de circular ampliamente como parte de sus imaginarios sociales, han tenido una traducción historiográfica.

Por un lado, en la posguerra los círculos académicos "progresistas" - que Lorenz" define ampliamente como democráticos y de izquierda -, enfrascados en la tarea de refundar el estado de derecho estableciendo una ruptura total con el pasado, percibieron a la guerra como un "manotazo de ahogado" de un régimen militar en crisis, que apeló a una "causa nacional" relevante para la sociedad argentina para recobrar su legitimidad. Se trataba, entonces, de una lectura del conflicto que replicaba la antinomia civil-militar de la Argentina posdictatorial, ya que se atribuía total responsabilidad del mismo a las FF.AA. en el poder, y explicaba el respaldo popular y masivo al desembarco como una respuesta automática y emotiva de la sociedad debido a la justicia de la causa nacional, y sobre todo debido a la manipulación de las FF.AA. y los medios de comunicación. Esta interpretación, que recogía un imaginario

11 Carassai, 2013.

12 Para un análisis crítico de este libro, ver Crenzel, 2013.

13 Lorenz, 2007. 
extendido en amplios sectores sociales y que continúa vigente aun hoy en distintas obras síntesis de la historia argentina o en libros específicos sobre la dictadura, percibe a la guerra como un momento excepcional de unidad nacional, de reencuentro entre la sociedad y el régimen, completamente disruptivo con la etapa previa al conflicto de "despertar de la sociedad civil" y con la eclosión social y el debacle militar que se produjo tras la derrota.

Además, se trata de una lectura que tanto subsume el Conflicto del Atlántico Sur a su coyuntura inmediata, como lo reduce a una interpretación política (solo fue una estrategia de legitimación de la dictadura militar), quitándole especificidad a la guerra como fenómeno social que, si bien se vincula a lo económico, político y cultural, tiene características propias. Esta perspectiva no toma a la guerra como objeto de estudio, a la que se interpreta apelando a ideas preconcebidas. ${ }^{14}$ Solo se interesa en la contienda bélica por las consecuencias que produjo la derrota en el campo social y político, pero no aborda las experiencias de los actores en la guerra en las islas ni en el continente. Por otro lado, una vasta historiografía militar ha sostenido una interpretación del conflicto radicalmente opuesta desde el término de la guerra. Desde un discurso patriótico clásico, ha propuesto una lectura de la guerra como "gesta" y de todos los combatientes como "héroes" por la lucha por la soberanía de un territorio propio. En esta mirada, la coyuntura inmediata -la dictadura militar- no tiene nada para aportar en la comprensión del conflicto, ya que este es incorporado a la línea de luchas patrióticas fundantes de la nación y por ende contextualizado sólo en el largo plazo desde la toma británica de las islas en 1833 . Se trata de una narrativa que busca legitimar a las FF.AA., ya que percibe a la guerra como un triunfo moral, por haberse atrevido a luchar contra una potencia imperialista histórica, más allá de la formación y de la más elemental evaluación de los recursos disponibles para ello; un discurso que, además, reivindica la movilización popular durante la guerra por su compromiso "patriótico" con la causa soberana.

Parte de esta historiografía consiste únicamente en resúmenes cronológicos de la guerra, análisis técnicos y operacionales del conflicto, crónicas de las batallas, entre otras, que si bien hacen referencia al devenir de la guerra en sí, las batallas y las unidades

14 Lorenz, 2011a. 
(a diferencia de la otra perspectiva), lejos están de buscar una comprensión situada y multidimensional de las experiencias de los combatientes en el conflicto, y menos aún hacen foco en las vivencias de aquellos que permanecieron en el continente o en el exilio. ${ }^{15}$

\section{Las potencialidades del cruce de temporalidades para la interpretación del pasado reciente}

Frente a estas limitaciones, a continuación abordaremos las potencialidades del diálogo entre múltiples escalas temporales para una comprensión más compleja del pasado reciente y, más aún, teniendo en cuenta que nuestros objetos de estudio refieren a las experiencias, prácticas, representaciones, subjetividades y modos de dar sentido por parte de los actores de la época. De esta manera, los cruces entre la larga, mediana y corta duración son tanto una elección teórico-metodológica que como investigadoras realizamos para pensar nuestros objetos de estudio, como también, son propios de/construidos por las trayectorias de los sujetos que investigamos.

La interpretación de las actitudes y comportamientos sociopolíticos de la gente corriente durante la última dictadura militar requiere pensar en temporalidades diversas ya que es preciso identificar cuáles fueron los factores que los motivaron y/o condicionaron y estos se inscriben en ciclos históricos distintos y/o en tendencias de distintas duraciones. Entre ellos, es especialmente relevante examinar las representaciones y marcos de sentido de dichos sectores sociales sobre dos dimensiones de sus experiencias históricas: las de la vida política y la violencia. ${ }^{16}$

Por una parte, en el análisis de las actitudes sociopolíticas en el período, debemos considerar el tiempo del acontecimiento y, como señala Traverso, su irreductible singularidad. ${ }^{17} \mathrm{El}$ sistema de desaparición forzada implantado por este régimen militar significó una novedad respecto de formas represivas anteriores. Es necesario, entonces, estudiar los efectos de esta ruptura sobre el conocimiento de dicho sistema

15 Sobre la historiografía de la guerra de Malvinas, ver Lorenz, 2011a, Lorenz \& Rodríguez, 2015.

16 Como plantea Emilio Crenzel, la lectura de la realidad "está mediada por los marcos de asimilación e interpretación de los sujetos", Crenzel, 2008: 39.

17 Traverso, 2003: 13. 
por parte de la gente corriente y sobre sus actitudes hacia la dictadura. El saber de los ciudadanos y las ciudadanas comunes sobre el plan represivo fue heterogéneo y fragmentario. Esto se debió a sus facetas públicas y a la vez ocultas, clandestinas, a la carencia de marcos dialógicos compartidos como consecuencia del quiebre de las relaciones sociales y, también, a la imposibilidad de darle un sentido integrado a los hechos de represión (ya sea experimentados, de los que fueron testigos o que conocieron de manera indirecta) dentro de los marcos de sentido de los que disponían, que habían sido elaborados en los años -e incluso décadas- previos. ${ }^{18}$ Entre los efectos que estas dificultades para elaborar un conocimiento acabado del sistema de desaparición forzada implementado por el régimen tuvieron sobre los comportamientos sociales hacia el régimen Crenzel señala, concretamente, que estas ponen en cuestión la existencia de una actitud hacia la represión "fruto de una elección deliberada o, eventualmente, como resultado de un mecanismo de negación inconsciente de carácter colectivo". ${ }^{19}$

Por otra parte, como señalamos, estos marcos de lectura de la realidad de los ciudadanos y ciudadanas de a pie se habían configurado en los años previos al golpe de Estado de 1976. Por ello, para comprender sus actitudes hacia el régimen militar es fundamental adoptar asimismo una perspectiva que se sitúe en la coyuntura y que indague en sus experiencias y representaciones en un tiempo más largo. Evaluar el período democrático anterior (1973-1976) nos permite considerar, entre otros, los efectos que, en los comportamientos sociales de adhesión y apoyo activo al golpe militar de parte de amplios sectores de la sociedad, tuvieron las percepciones construidas en esos años precedentes sobre la existencia de una situación de anomia, caracterizada por la escalada de violencia política, el derrumbe institucional del gobierno y la crisis económica. En particular, este enfoque nos permite reconocer los discursos políticos y periodísticos que circularon en esos años y el conjunto de sentidos que configuraron sobre el "problema de la violencia". ${ }^{20}$ Como señala Marina Franco, "la prensa comercial independiente contribuyó desde muy temprano a construir una realidad específica: 'el imperio de la

18 Crenzel, 2010.

19 Crenzel, 2010: 94.

20 Franco, 2012. 
violencia" ${ }^{21}$ y presentó una "discursividad política mayoritariamente proclive a la salida represiva frente a la violencia". 22 Las construcciones mediáticas de representaciones homogeneizadoras sobre este fenómeno, desprovistas de toda distinción analítica y de todo marco explicativo, contribuyeron a ocultar cada vez más los intensos procesos de conflictividad política de la época bajo una totalidad vacía y atemorizante: "la violencia". ${ }^{23}$

Un análisis asentado en un marco temporal más amplio permite explorar algunos de los efectos que este universo de sentidos que circulaban públicamente en los años previos tuvo sobre las representaciones y experiencias contemporáneas de la gente corriente y, también, estudiar los vínculos con sus percepciones y actitudes sociopolíticas frente al golpe militar y, en especial, frente a la "lucha contra la subversión". Concretamente, estos marcos de lectura configurados en los años previos ligados a dichas lecturas homogeneizadoras sobre la "violencia" -en las que no se diferenciaba a sus actores, sus posicionamientos, las razones de los conflictos políticos y sociales y de los enfrentamientos-, se sumaron a las dificultades de las personas comunes para construir un conocimiento integrado sobre la represión instalada por el régimen militar.

Una indagación situada en esta coyuntura también nos permite sopesar otra variable: la existencia de una demanda de "orden" dirigida hacia el Estado, que es propia de toda sociedad y que operó en esta coyuntura sobre las actitudes sociopolíticas de estos sectores sociales. Como señala Franco, existió un "consenso social en favor de la represión ejercida por el Estado, en tanto este funciona en las representaciones sociales como garante de la legalidad'. ${ }^{24}$ En este sentido, respecto de las sociedades autoritarias del Cono Sur, Lechner ha planteado que el autoritarismo encarna una demanda y un deseo vital de orden frente a una situación de caos, frente al miedo ante una vida que es percibida sin sentido, futuro ni bases normativas. ${ }^{25} \mathrm{El}$ autoritarismo es la respuesta a esta situación de incertidumbre. Siguiendo a este autor, Vezzetti afirma, asimismo, que "no hay sociedad que soporte largos periodos de extrema inestabilidad e imprevisibilidad y la intervención autoritaria

21 Franco, 2012: 199.

22 Franco, 2012: 189.

23 En este sentido, y para el caso del diario La Nueva Provincia de Bahía Blanca, ver Seitz, 2021.

24 Franco, 2015: 75-76.

25 Lechner, 1992. 
sirve, en ese sentido, para proporcionar al desorden y a la inestabilidad un origen claro, atribuible a una causa visible". ${ }^{26}$

Las percepciones y las vivencias en las que se basaron los comportamientos sociales frente a la instauración del régimen militar y a su permanencia también deben ser evaluados en un lapso de tiempo más largo, dentro de un ciclo de activación política, social y cultural y de radicalización y protesta social que desborda una cronología centrada en el gobierno democrático anterior al abrirse en 1969 con el "Cordobazo" y los subsiguientes "azos". ${ }^{27}$ En este marco temporal situado en la coyuntura, una discusión relevante a considerar es la de la existencia -o no-, en la década de 1960 y a comienzos de la década de 1970, de un extendido consentimiento, aceptación tácita o simpatía de parte de amplios sectores sociales hacia la violencia revolucionaria y los grupos guerrilleros. ${ }^{28}$

De igual manera, dado que el autodenominado "Proceso de Reorganización Nacional" duró casi 8 años, la interpretación de los comportamientos sociales no puede quedar circunscripta a su configuración en el momento del golpe y los primeros tiempos de instauración de la dictadura. Las actitudes sociopolíticas de la gente corriente frente a regímenes no democráticos son dinámicas y cambiantes. ${ }^{29}$ Su estudio durante la última dictadura militar en Argentina debe necesariamente historizar las transformaciones que se fueron produciendo en ellas en función del desarrollo de distintos procesos políticos, económicos y sociales, de las políticas implementadas por el régimen, de acontecimientos diversos, etc. Por ejemplo, en el caso argentino, es necesario estudiar el impacto en dichas conductas de momentos históricos como el Campeonato Mundial de Fútbol, la visita de la Comisión Interamericana de Derechos Humanos y la guerra de Malvinas (la cual será abordada más adelante), entre otros.

La integración de análisis situados en distintas duraciones temporales, además, permite -desde la perspectiva de la vida cotidiana- poner en tensión las periodizaciones que

26 Vezzetti, 2003: 51. Para el caso del nazismo, Peukert ha señalado, en un sentido similar, que la más profunda razón para el consentimiento dado por la mayoría de la población al régimen nazi fue el anhelo de normalidad sentido por una población que había sido sacudida por crisis y cuyos puntos sociales de referencia habían sido arrojados al desorden: Peukert, 2012.

27 Brennan \& Gordillo, 2008, Gordillo, 2019.

28 Para una evaluación del conjunto de informaciones e interpretaciones en las que se basa este debate ver Lvovich, 2020.

29 Saz Campos en: Durán et al, 2014, Hernández Burgos, 2013. 
distinguen períodos democráticos y dictatoriales. En primer lugar, una escala temporal de mediano plazo hace posible relativizar los cortes institucionales y subrayar las continuidades "en términos de prácticas represivas estatales que configuraron, desde 1973 y tras un breve intervalo, un estado de excepción creciente que se integró, con diferencias, en el ciclo autoritario conformado por la dictadura militar que se inició en 1976". ${ }^{30}$ Pero, por otra parte, un examen de más largo plazo permite reconocer que las experiencias y representaciones de la gente corriente se construyeron a lo largo de un ciclo de alternancia de regímenes políticos democráticos y dictatoriales que se inició en 1930 y en el que se configuró un largo debilitamiento de las formas de la democracia institucional y, a la par, una cotidianeidad y unas vivencias y percepciones de la vida política en la que la presencia de las Fuerzas Armadas en el gobierno y la existencia de un régimen autoritario fueron parte de la "normalidad" diaria.

Por último, una perspectiva de largo plazo también nos permite reconocer que la dictadura se sustentó en una cultura política previa, de larga tradición en nuestro país, definida por el autoritarismo y la negación del otro. ${ }^{31}$

En el caso del Conflicto del Atlántico Sur, los cruces entre distintas temporalidades son casi obligatorios para el investigador ya que son inherentes al propio objeto de estudio. En otras palabras, en tanto nos situamos en una perspectiva sociocultural de lo bélico, partimos de la comprensión de la guerra como un fenómeno social y cultural, que si bien tiene vinculaciones con otros ámbitos de la vida humana, tiene atributos que les son propios. Dicho enfoque propone abordar los sentidos que los contemporáneos han construido sobre el conflicto (materializándolos en prácticas, expresiones artísticas, literatura, entre otras), en tanto concibe que esas representaciones del conflicto "se cristalizan en un sistema de pensamiento que le dan a la guerra su significación profunda". ${ }^{32}$

Desde dicha perspectiva, que implica un giro de $180^{\circ}$ de la historia política, militar y diplomática tradicional sobre la guerra - que no prestaba atención a la vivencia de los "sujetos en guerra" 33 -, el diálogo entre distintas escalas temporales resulta nodal para

30 Franco, 2012: 16.

31 Romero, 2006, Calveiro, 2008.

32 Audoin - Rouzeau \& Becker, 2002: 102 (traducción propia). Sobre la historia sociocultural de la guerra y posguerra de Malvinas, ver Rodríguez, 2017.

33 González Calleja, 2008. 
comprender las experiencias, memorias e identidades de los actores atravesados por la contienda bélica. En tal sentido, hay que tener presente que si bien toda guerra es una experiencia límite y excepcional - ya que incluye situaciones "ante las cuales no hemos sido preparados, socializados, iniciados" 34 porque las normas y valores que rigen los tiempos de paz son subvertidos en tiempos bélicos-, ello no significa que los actores no traten de dar sentido a esas vivencias a partir de aquellas matrices de sentido construidas históricamente sobre lo que es la guerra y la violencia, que orientan a los actores en su presente, entre un pasado y un futuro esperable. Como indica Horne ${ }^{35}$ para la Primera Guerra Mundial, las movilizaciones bélicas implican no solo dimensiones militares y económicas (como son pensadas tradicionalmente), sino también culturales y políticas, e incluyen apelaciones a valores, tradiciones y la identidad nacional, que forman parte de los marcos de lectura de los contemporáneos. Y claro que esas movilizaciones no solo son conducidas desde los regímenes y gobiernos "desde arriba", sino que también envuelven esfuerzos privados, individuales y colectivos de los ciudadanos "desde abajo", que promueven todo tipo de acciones por motus propio (aunque ello varía a lo largo del conflicto en función de múltiples factores).

Por ende, para volver inteligibles las experiencias de los actores que permanecieron en el continente durante la guerra de Malvinas y lograr una mirada más compleja que aquellas que los etiquetan o como marionetas de la dictadura o como patriotas sin miramientos ni raciocinio, es necesario apelar a distintas temporalidades.

Las múltiples movilizaciones populares, en gran parte espontáneas y autoconvocadas (aunque en ocasiones fueron rápidamente encauzadas por las distintas instancias gubernamentales) que se produjeron ni bien iniciado el conflicto, ${ }^{36}$ son imposibles de comprender si no tenemos en cuenta procesos culturales y políticos de largo plazo como la construcción de la reivindicación de la soberanía del archipiélago como una causa nacional por lo menos desde la década de 1930 (aunque hay antecedentes

34 Da Silva Catela, 2006:11.

35 Horne, 1997.

36 Para análisis generales sobre las actitudes sociales frente al conflicto, ver Guber, 2001, Lorenz, 2006 y para el exilio ver: Jensen, 2007. Para estudios situados en espacios locales, ver Rodríguez, 2007 sobre Bahía Blanca; Pratesi, 2010 sobre el Chaco; Lorenz, 2011b sobre Río Grande (Tierra del Fuego); Martínez \& Olivares, 2013 sobre Comodoro Rivadavia (Chubut). Específicamente, sobre la prensa frente al conflicto, ver Escudero, 1996, Borrelli, 2008, Gago \& Saborido, 2011, Gamarnik, 2015, Tato, 2020. Sobre la Iglesia Católica, Obregón, 2007; sobre los partidos políticos, Yanuzzi, 1997; sobre la izquierda, Gilly, Woods \& Bonnet, 2012. 
previos), apropiada por amplios sectores sociales, que durante generaciones aprendieron en las escuelas y en el servicio militar obligatorio que "Las Malvinas fueron, son y serán argentinas" casi como un mandato. La "causa nacional" se arraigaba (y a la vez reforzaba) en la concepción de Inglaterra como una potencia imperialista que desconocía los derechos de países más débiles y recientes como Argentina, un sentido que retomaba una historia que se remonta por lo menos a las invasiones inglesas. Todas estas representaciones se actualizaron en el contexto de la guerra, que - desde el patriotismo tradicional - fue concebida como una nueva gesta libertadora de la nación y, a la vez, como posibilidad de refundar una Argentina libre de conflictos y fricciones. ${ }^{37}$ Asimismo, el sentido construido sobre las nociones de guerra y combatiente por parte de los contemporáneos del Conflicto del Atlántico Sur se anclan en representaciones de larguísima duración sobre los atributos de un guerrero, de la violencia legítima a aplicarle al otro y de la guerra -que incluso forman parte del imaginario bélico occidental en el siglo XX. ${ }^{38}$

Sin embargo, esta explicación reducida a la larga duración no alcanza. Sin dudas, factores propios de la coyuntura histórica de la guerra tienen mucho que aportar para la comprensión cabal de dichas actitudes y para desmentir la concepción de los ciudadanos como marionetas de la dictadura, como la necesidad de amplios sectores sociales de conquistar un espacio público que había estado brutalmente vetado por años (que volvieron a ocupar las plazas masivamente) así como la censura que regía que no habilitaba el espacio para voces disidentes. ${ }^{39}$ En tal sentido, el rol de la prensa durante el conflicto no puede comprenderse si no lo vemos a la luz de los distintos comportamientos que venían adoptando los medios de comunicación ante las políticas de "acción psicológica" implementadas por las FF.AA. desde el golpe de estado en 1976, y aún mucho más atrás. ${ }^{40}$ Por otro lado, si nos centramos en las experiencias de los patagónicos, en ocasiones, los sentidos que dieron a sus prácticas en 1982 estuvieron anclados - e incluso teñidos - por su movilización en 1978, cuando las poblaciones del sur se prepararon para combatir contra Chile. ${ }^{41}$

37 Guber, 2001, Lorenz, 2006.

38 Rodríguez, 2020.

39 Guber, 2001, Lorenz, 2006.

40 Risler, 2018.

41 Lorenz, 2011, Martínez \& Olivares, 2013. 
Asimismo, si nos situamos en el análisis de las expresiones públicas durante la guerra - en el nivel acontecimental -, podríamos incorporar matices, al identificar cuál era realmente el objeto del apoyo popular: ¿El desembarco en las islas, la guerra, la dictadura, la causa de soberanía, los soldados en las islas? ¿ $\mathrm{O}$ todo ello al mismo tiempo? ¿El respaldo masivo a la guerra y/o a la "causa nacional” implicaba desconocer y silenciar los cuestionamientos a la dictadura en otros planos? Como indica Lorenz, la guerra llevaba implícita una contradicción: “eera posible disociar un hecho festejado y considerado legitimo del poder que lo habia producido?". ${ }^{2}$ Los modos en que los contemporáneos - tanto en Argentina como en el exilio - lidiaron con esa contradicción fueron diversos. Algunos separaron tajantemente la guerra de la dictadura que le dio origen por la legitimidad de la causa (al fin y al cabo, se trataba de una "guerra antiimperialista" y justa). Otros se opusieron a tal distinción: la guerra no era legítima porque era una "maniobra dictatorial" para perpetuarse en el poder y desnudaron los engaños del patriotismo. ${ }^{43}$ Entre ambos extremos, existieron los más diversos matices como, por ejemplo, aquellos que continuaron denunciando a la dictadura por la represión ilegal, la urgente normalización institucional y/o por su política económica pero defendiendo la causa de soberanía de las islas, o aquellos que solo se movilizaban en solidaridad de los soldados apostados en el archipiélago. ${ }^{44}$ Por último, si estudiamos de forma situada y micro esas actitudes, también podemos complejizar aún más este panorama teniendo en cuenta otros dos factores. Por un lado, reconociendo otras motivaciones detrás del apoyo. Por ejemplo, en las cartas enviadas al régimen por parte de ciudadanos argentinos que se ofrecían a poblar las islas en el marco del conflicto, encontramos no solo causas políticas - el respaldo a la soberanía de las islas - sino también otras motivaciones personales y económicas (de personas que veían al archipiélago como un lugar para salir de la cruda crisis económica), en el marco de un imaginario de larga data de la Patagonia como espacio de esperanzas, de realización nacional. ${ }^{45}$ Por otro lado, historizando esas actitudes en el cortísimo plazo e identificando continuidades y rupturas a lo largo de los 74 días del conflicto, en

42 Lorenz, 2009: 57.

43 Jensen, 2007.

44 Guber, 2001, Lorenz, 2006, Pratesi, 2010.

45 Lorenz, 2014, Pratesi, 2010. 
función del avance de la guerra, de las idas y vueltas diplomáticas, de las noticias que llegaban al continente, entre otras.

Entonces, el cruce entre estas temporalidades nos permite identificar las continuidades y rupturas en los comportamientos de diversos actores sociales frente a la guerra, lo que nos ayuda a interpretar el tan debatido apoyo popular al desembarco (incluso de sectores que se habían opuesto a/distanciado de la dictadura) en toda su complejidad. En tal sentido, esta mirada nos permite resituar ese respaldo social en la larga duración histórica y comprender las motivaciones de los actores desde allí: como indicamos, por la justicia de la causa nacional construida a lo largo del siglo XX, la imagen del enemigo, la oportunidad de unidad nacional tras años de conflictos.

Sin embargo, una mirada que solo se redujera a esa temporalidad, podría considerar el respaldo al conflicto como una consecuencia casi natural y previsible. Por ello, resulta fundamental incorporar también el diálogo con las otras duraciones, y situar a la guerra en la coyuntura dictatorial, lo que nos permite comprender las complejidades, matices e incluso contradicciones de los comportamientos de algunos actores, para quienes la guerra significó la posibilidad de recuperar las calles y los lazos políticos cortados por la dictadura, o que, en algunos casos, dieron su consenso al desembarco pero continuaron sosteniendo sus cuestionamientos al régimen. Por ende, este cruce de duraciones nos obliga a discutir la imagen de la supuesta unidad nacional durante el conflicto (lo que convertiría a la contienda en un momento excepcional que nada tiene que ver con el antes y después de la guerra) y nos invita a resituar la conflictividad en la sociedad durante la contienda.

Por otro lado, como indicamos, en otros casos son las propias trayectorias de los actores las que construyen esos cruces temporales, ya que en sus prácticas sociales significan y producen en forma cotidiana diferentes lógicas temporales, incluso -en ocasiones- poniendo en cuestión las cronologías tradicionales establecidas por la historiografía.

Por caso, en los relatos de gran parte de los actores atravesados por el conflicto, la guerra empezó mucho antes del 2 de abril, cuando aprendieron un sentido sobre la “causa Malvinas” ligado a la identidad nacional, y aún no terminó, no sólo porque las islas todavía no se reintegraron al patrimonio nacional sino porque las luchas por la memoria de Malvinas siguen vigentes en la esfera pública. Por ende, el énfasis en las 
vivencias de los actores atravesados por la guerra, en su agencia, no sólo complejiza, sino que también subvierte y cuestiona el relato técnico, colectivo y uniforme militar que tiene un comienzo y fin determinado, estrictamente delimitado por las operaciones en el teatro bélico. ${ }^{46}$

En las memorias de ciudadanos de a pie sobre sus prácticas y percepciones durante la dictadura iniciada en 1976 y en los años inmediatamente previos, también encontramos distintas temporalidades que desbordan el período investigado. Algunos, por ejemplo, remiten su preocupación por tomar distancia y ser indiferentes frente a lo "político" en la década del setenta, a las experiencias vividas durante el golpe militar de 1955 y, previamente, en el bombardeo de Plaza de Mayo en junio de dicho año.

\section{A modo de cierre}

A partir de nuestras investigaciones sobre las actitudes sociopolíticas de la gente corriente durante la última dictadura militar y sobre las experiencias de quienes permanecieron en el continente en la guerra de Malvinas, en este trabajo nos propusimos reflexionar en torno a las potencialidades para la interpretación histórica que generan los diálogos entre distintas duraciones en los estudios sobre el pasado reciente centrados en los actores (en sus experiencias, representaciones e identidades). Más aún cuando son los propios sujetos-objetos de estudio los que en sus prácticas y en los sentidos que construyen realizan esos cruces. En este último apartado, nos proponemos explorar al menos dos núcleos en común vinculados a las temporalidades que atraviesan a ambas investigaciones y que pueden contribuir a la comprensión tanto de las dimensiones sociales de la última dictadura militar, como de las movilizaciones en la guerra de Malvinas y las experiencias de los sujetos atravesados por ella.

En primer lugar, centrándonos en una perspectiva de más larga duración, la reconstrucción de los imaginarios de guerra y de la violencia que se habilita a aplicar a "otro" son aspectos que son centrales para nuestros objetos de estudio. En tal sentido, sin dudas la tan mentada existencia de una cultura política que concibe a todo conflicto político y social como guerra y al adversario como un otro a eliminar, ajeno a la nación

46 Hynes, 1999. 
(que ha sido propia tanto de las FF.AA. como de los principales movimientos políticos en el siglo XX), son algunas de las variables fundamentales para la comprensión de las actitudes sociales frente a la guerra "antisubversiva" y a la de Malvinas. ${ }^{47}$ Sin embargo, esa explicación es tan sugerente como insuficiente, no sólo porque hacen falta estudios que den carnadura histórica y profundicen en la conformación y cambios de dichas representaciones en distintos contextos históricos, sino también porque hacen falta otras variables de corta y mediana duración para volver inteligibles dichas vivencias. En segundo lugar, otro núcleo vinculado a la corta y también a la mediana duración, refiere a la restricción que el régimen dictatorial operó sobre el espacio público. Las primeras medidas implantadas por el régimen y la intensidad de la represión y el miedo instaurado generaron, en la gente corriente, unas actitudes de refugio en la vida privada, de quiebre o limitación de las relaciones sociales y de silencio. Sin embargo, un análisis de más largo plazo, que observe todo el período permite, en principio, reconocer que este marco autoritario también habilitó ámbitos comunitarios en los que algunos sectores sociales pudieron desarrollar una gran diversidad de actividades públicas y movilizaciones políticas. ${ }^{48}$ Asimismo, posibilita identificar la instrumentación por parte del régimen no sólo del terror y la represión, sino también de distintas estrategias destinadas a producir un consenso activo en la sociedad. En este sentido, una perspectiva temporal más amplia hace posible considerar, también, los modos en que estas fueron transformándose a lo largo del período, en función de los cambios que se fueron produciendo en el consenso social inducido por la dictadura. ${ }^{49}$

De hecho, la guerra de Malvinas fue una de las últimas estrategias de legitimación del régimen y el amplísimo apoyo social al desembarco demuestra que en un comienzo fue exitosa. De todas formas, las diversas motivaciones, complejidades y matices que identificamos detrás de las movilizaciones sociales para contribuir al esfuerzo bélico (que lejos estuvieron de significar en forma unilateral un consenso sobre el conflicto y

47 Sobre estos atributos de la cultura política argentina, ver Ansaldi, 2000. En cuanto a las representaciones sociales sobre los adversarios políticos como ajenos al territorio y/o al "ser nacional" y como una "amenaza subversiva" a principios del siglo XX en relación al anarquismo, y las formas en que luego fue encarnado por actores diversos en distintas coyunturas, ver Franco, 2019. Específicamente, sobre la circulación de la noción de guerra en el espacio público en los setenta, consultar Vezzetti, 2003, Franco, 2012.

48 Para el caso de las asociaciones judías, ver Kahan, 2014.

49 Risler \& Schenquer, 2018, Schenquer \& Cañada, 2020. 
menos aún sobre la dictadura), nos da la pauta de la necesidad de resituar los comportamientos sociales siempre en distintos contextos que respondan a temporalidades diversas. Por caso, la reclusión al ámbito privado que caracterizó a la dictadura -con los límites y matices señalados- es una de las variables que nos ayudan a comprender la gran movilización que acompañó la guerra de Malvinas, no solo por lo que significaba esa causa nacional para la gran mayoría de la sociedad argentina, sino porque el espacio habilitado por el régimen militar a partir del 2 de abril de 1982 fue apropiado por distintos actores sociales con distintas motivaciones, incluso contrarias a la dictadura.

En este texto nos propusimos dar cuenta de las potencialidades que una indagación que integra distintas temporalidades tiene en la interpretación del pasado reciente. Retomando nuevamente los planteos de Traverso, consideramos que uno de los principales desafíos de esta perspectiva es el de lograr que la singularidad del acontecimiento no quede diluida en el esfuerzo por reconocer las tendencias de mediano y largo plazo en que se inscribe y, por otra, que una comprensión centrada en la evaluación de la especificidad de lo acontecido en el tiempo corto no nos impida reconocer la estabilidad y permanencia de determinadas tendencias, por ejemplo, como señalamos, en el nivel de las representaciones sociales. 


\section{BIBLIOGRAFÍA}

Aguirre Rojas, C. 1999, La escuela de los Annales: ayer, boy y mañana, Montesinos, Madrid.

Ansaldi, W. 2000, "La trunca transición del régimen oligárquico al régimen democrático" en Falcón R. Democracia, conflicto social y renovación de ideas (1916-1930), Sudamericana, Buenos Aires.

Aróstegui, J. 2004, La historia vivida. Sobre la bistoria del presente, Alianza, Madrid.

Audoin - Rouzeau, S. \& Becker, A. 2002, 1418. Understanding the Great War, Hill and Wang, New York.

Bergerson, A. S. 2004, Ordinary Germans in extraordinary times. The Nazi Revolution in Hildesheim, Indiana University Press, Bloomington.

Brennan, J. \& Gordillo, M. 2008, Córdoba rebelde: el cordobazo, el clasismo y la movilización social, De la Campana, La Plata.

Borrelli, M. 2008, "El Diario de Massera". Historia y política editorial de Convicción: la prensa del "Proceso", Koyatun, Buenos Aires.

Carassai, S. 2013, Los años setenta de la gente común. La naturalización de la violencia, Siglo XXI, Buenos Aires.

Calveiro, P. 1998, Poder y desaparición. Los campos de concentración en la Argentina, Ed. Colihue, Buenos Aires.

Crenzel, E. 2008, La historia politica del Nunca Más. La memoria de las desapariciones en la Argentina, Siglo XXI, Buenos Aires.

Crenzel, E. 2010, "Memorias de las desapariciones. Los vecinos del Centro Clandestino de Detención del Hospital Posadas, Buenos Aires, Argentina" en Revista Crítica de Ciências Sociais, Núm. 8, pp.79 a 99.

Crenzel, E. 2013, “Sebastián Carassai, Los años setenta de la gente común. La naturalización de la violencia, Buenos Aires, Siglo XXI, 2013, 329 p." en Nuevo Mundo Mundos Nuevos. Disponible en: http://journals.openedition.org/nuevomundo \66159 [Consulta: 02 septiembre 2020].

Da Silva Catela, L. 2006, "Presentación", en Pollak, M. Memoria, olvido, silencio. La producción social de identidades frente a situaciones límites, $\mathrm{Al}$ Margen, La Plata.

Durán, V. Iglesias, F. Ríos, S. Schenquer, L. \& Seitz, A. I. 2014, "Decir no sólo miedo y represión quiere decir que también el miedo y la represión formaron parte del franquismo.
Entrevista con Ismael Saz Campos" en Páginas. Revista Digital de la Escuela de Historia, año 6, Núm. 10, pp. 151 a 161.

Escudero, L. 1996, Malvinas: el gran relato. Fuentes $y$ rumores en la información de guerra, Gedisa, Barcelona.

Franco, M. 2012, Un enemigo para la nación. Orden interno, violencia y subversión, 1973-1976. Prometeo, Buenos Aires.

Franco, M. 2014, "La noción de 'dictadura cívico-militar"” en Flier, P. (comp.) Mesas de debate de las VII Jornadas de Trabajo sobre Historia Reciente, Facultad de Humanidades y Ciencias de la Educación, La Plata, pp. 69 a 90.

Franco, M. 2015, "La 'teoría de los dos demonios' en la primera etapa de la posdictadura" en Feld, C. \& Franco, M. (dirs.) Democracia, hora cero. Actores, políticas y debates en los inicios de la posdictadura, Fondo de Cultura Económica, Buenos Aires.

Franco, M. 2019, "En busca de la "guerra fría". Culturas políticas, procesos locales y circulaciones de largo plazo" en Prismas. Revista de historia intelectual, Núm. 23, pp. 181 a 187.

Franco, M. \& Levin, F. (comps.) 2007, Historia reciente. Perspectivas y desafíos para un campo en construcción, Paidós, Buenos Aires.

Gago, M. P. \& Saborido, J. 2011, “Somos y Gente frente a la guerra de Malvinas: dos miradas en una misma editorial" en Saborido, J. \& Borelli, M. (coord.) Voces y silencios: la prensa argentina y la dictadura militar (1976-1983), Buenos Aires, Eudeba.

Gamarnik, C. 2015, “La fotografía de prensa durante la guerra de Malvinas: la batalla por lo (in) visible" en Páginas, año 7, Núm. 13.

Gilly, A. Woods, A. \& Bonnet, A. 2012, La izquierda y la guerra de Malvinas, Razón y Revolución, Buenos Aires.

González Calleja, E. 2008, "La cultura de guerra como propuesta historiográfica: una reflexión general desde el contemporaneísmo español" en Historia Social, Núm. 61.

Gordillo, M. (comp.) 2019, 1969. A cincuenta años. Repensando el ciclo de protestas, Córdoba y Buenos Aires, Universidad Nacional de Córdoba y CLACSO, Buenos Aires.

Guber, R. 2001, ¿Por qué Malvinas? De la causa nacional a la guerra absurda, FCE, Buenos Aires.

Hernández Burgos, C. 2013, Franquismo a ras del suelo. Zonas grises, apoyos sociales y actitudes durante la dictadura (1936-1976), Editorial Universidad de Granada, Granada. 


\section{A. B. Rodríguez \& A. I. Seitz \\ 26/27: pp.147-169 \\ Cuadernos de Historia. Serie economía y sociedad}

Horne, J. 1997, "Introduction: mobilizing for “total war", 1914-1918" en Horne, J. (ed.) State, society and mobilization in Europe during the First World War, University of Cambridge, Cambridge.

Hynes, S. 1999, "Personal narratives and commemoration" en Winter, J. \& Sivan, E. War and Remembrance in the Twentieth Century, University of Cambridge. Cambridge.

Jensen, S. 2007, “Guerra antiimperialista o maniobra dictatorial? Malvinas como dilema para los exiliados" en Revista Puentes, Núm. 20.

Kahan, E. 2014, Recuerdos que mienten un poco. Vida y memoria de la experiencia judía durante la última dictadura militar, Prometeo, Buenos Aires.

Lechner, N. 1992, "Some people die of fear. Fear as a political problema" en Corradi, J. Weiss Fagen, P. \& Garretón, M. A. (eds.) Fear at the edge. State terror and resistance in Latin America, University of California Press, Berkley and Los Angeles.

Lorenz, F. 2006, Las Guerras por Malvinas, Edhasa, Buenos Aires.

Lorenz, F. 2007, "La necesidad de Malvinas", en Revista Puentes, Núm. 20.

Lorenz, F. 2009, Malvinas. Una guerra argentina, Sudamericana, Buenos Aires.

Lorenz, F. 2011a, "El malestar de Krímov. Malvinas, los estudios sobre la guerra y la historia argentina reciente" en Estudios, Núm. 25 , pp. 47 a 65.

Lorenz, F. 2011b, “Otras marcas. Guerra y memoria en una localidad del sur argentino (1978-1982)" en Bohoslavsky, E. et al. (eds.) Problemas de Historia Reciente en el Cono Sur, Editorial UNGS-Prometeo, Buenos Aires.

Lorenz, F. 2014, "Veinte mil argentinos en un barco. Cartas de voluntarios para poblar las islas recuperadas, abril" en Corpus, Vol. 4, Núm. 1.

Lorenz, F. y Rodríguez, A. B., 2015, "La guerra de Malvinas: experiencias, historia y memoria" en Páginas, año 7, Núm. 13.

Lvovich, D. 2013, “Actitudes sociales y dictaduras: las historiografías española y argentina en perspectiva comparada", en Águila, G. \& Alonso, L. (coord.) Procesos represivos y actitudes sociales. Entre la España franquista y las dictaduras del Cono Sur, Prometeo, Buenos Aires.

Lvovich, D. 2018, "Actitudes sociales bajo la última dictadura militar: un análisis crítico de la producción historiográfica" en Águila, G.
Luciani L. Seminara, L. \& Viano C. (comps.) La bistoria reciente en Argentina. Balances de una bistoriografía pionera en América Latina, Imago Mundi, Buenos Aires, pp. 71 a 91.

Lvovich, D. 2020, “¿Cerca de la revolución? Datos cuantitativos e interpretaciones de las encuestas sobre las distintas modalidades de apoyo a la violencia revolucionaria en Argentina, 1970 - 1973" en Izquierdas, Núm. 49, pp. 952 a 967.

Martínez, J. \& Olivares, M. J. 2013 "Vida cotidiana y participación ciudadana: la sociedad comodorense durante la Guerra de Malvinas" en Textos y Contextos desde el sur, año 1, Núm. 1.

Montero, A. S. 2016, "El objeto discursivo 'dictadura cívico-militar' en la Argentina reciente: narrativas históricas y sentidos contemporáneos" en Crítica contemporánea. Revista de Teoría politica, Núm. 6, pp. 53 a 77.

Obregón, M. 2007, "La Iglesia Católica durante la guerra del Atlántico Sur" en Cuadernos de Argentina Reciente, Núm. 4.

Peukert, D. 1992, Inside Nazi Germany. Conformity, opposition and racism in everyday life, Yale University Press, New Haven and London.

Pratesi, A. R. 2010, Una pasión recorre el Chaco. Malvinas, nación, dolor, Ediciones del Autor, Resistencia.

Risler, J. 2018, La acción psicológica. Dictadura, inteligencia y gobierno de las emociones (1955-1981), Tinta Limón, CABA.

Risler, J. \& Schenquer L. 2018, “La realización de sondeos y encuestas de opinión pública durante la gestión del General Viola en la última dictadura militar (1981)" en Sociobistórica, Núm. 42.

Rodríguez, A. B. 2007, "Memorias bahienses de la Guerra de Malvinas: la guerra y la cotidianeidad" en Actas de las XI Jornadas Interescuelas- Departamentos de Historia, Universidad Nacional de Tucumán, Tucumán.

Rodríguez, A. B. 2017, "Por una Historia Sociocultural de la guerra y posguerra de Malvinas. Nuevas preguntas para un objeto de estudio clásico" en PolHis, año 10, Núm. 20.

Rodríguez, A. B. 2020, Batallas contra los silencios. La posguerra de los ex combatientes del Apostadero Naval Malvinas, UNGS/ UNLP/ UNM, Buenos Aires/ Los Polvorines/ La Plata/ Posadas. 
Romero, L. A. 2001, "Las raíces de la dictadura. La sociedad como cómplice, partícipe o responsable" en Revista Puentes, año 1, Núm. 3. Saborido, J. \& Borelli, M. (coords.) 2011, Voces y silencios: la prensa argentina y la dictadura militar (1976-1983), Eudeba, Buenos Aires.

Schenquer, L. \& Cañada, L. 2020, "Monumentos, marcas y homenajes: la última dictadura, los usos del pasado y la construcción de narrativas autolegitimantes (Buenos Aires, 1979-1980)" en Quinto Sol, Núm. 24, Vol. 2, pp. 1 a 20.

Seitz, A. I. 2015, "Desafíos metodológicos en el abordaje de las actitudes sociales en dictadura (Argentina, 1976-1983). Apuntes para un campo de estudio en construcción" en Actas de las Sextas Jornadas de Historia de la Patagonia, EDUCO, Universidad Nacional del Comahue, Neuquén.

Seitz, A. I. 2021, "Prensa y representaciones sociales. Lecturas sobre la "violencia" en el diario La Nueva Provincia (Bahía BlancaArgentina, 1972-1976)" en XI Jornadas de Historia Moderna y Contemporánea, Universidad Nacional del Sur, Bahía Blanca.

Tato, M. I. \& Dalla Fontana, L. E. (dirs.) 2020, La cuestión Malvinas en la Argentina del Siglo XX. Una historia social y cultural, Prohistoria, Rosario.

Traverso, E. 2003, La violencia nazi. Una genealogía europea, FCE, México.

Vezzetti, H. 2003, Pasado y Presente. Guerra, dictadura y sociedad en la Argentina. Siglo XXI, Buenos Aires.

Yanuzzi, M. A. 1996, Politica y dictadura. Los partidos políticos y el "Proceso de Reorganización Nacional” (1976-1983), Fundación Ross, Rosario. 